\title{
LA SOLUCIÓN AMISTOSA DE PETICIONES DE DERECHOS HUMANOS EN EL ÁMBITO UNIVERSAL Y REGIONAL, CON ESPECIAL REFERENCIA AL SISTEMA INTERAMERICANO
}

\author{
Jorge Ulises CARMONA TINOCO*
}

\begin{abstract}
RESUMEN: Uno de los mecanismos internacionales de supervisión de los Estados en materia de derechos humanos es la presentación de peticiones individuales e interestatales ante organismos internacionales. Una de las formas cada vez más recurrentes de resolver este tipo de peticiones es la posibilidad expresa o implícita de solucionarlas de forma amistosa entre los Estados involucrados, o entre el Estado involucrado y la víctima o sus representantes, bajo la supervisión internacional de un órgano internacional. El presente trabajo se centra en la solución amistosa de peticiones, en especial las de carácter individual en el marco de los sistemas universales y regionales de derechos humanos (europeo, africano e interamericano), con el fin de determinar sus orígenes y perspectivas, al igual que su funcionamiento práctico e incidencia, así como explorar algunos cuestionamientos acerca de su pertinencia y viabilidad en ciertos casos de violaciones a los derechos humanos.
\end{abstract}

ABSTRACT: One of the international supervision mechanisms the States use regarding human rights is the presentation of individual and interstate petitions before international organisms. An even more common way of solving this kind of petitions is through an amicable solution under international supervision of an international organ. The present work focuses on the pacific solution of petitions, specially those with individual character within the universal and regional human rights systems (European, African and Interamerican). It aims to determine their nature and perspectives, as well as their practical character and capacity of incidence. Moreover, it tries to explore some issues regarding their importance and feasibility in certain cases of human rights violations.

RÉSUMÉ: Un des mécanismes de supervision internationale que les États utilisent dans les cas des droits de l'homme est la présentation des pétitions individuelles et entre les États dans les organismes internationaux. Une manière plus commune pour résoudre ces pétitions est en donnant une solution amicale avec la supervision internationale d'un organisme international. Cet article déroule la solution pacifique des pétitions, de façon particulière, les individuelles dedans le système universel et régional de droits de l'homme (Européenne, Africaine, et Interamericaine). L'objectif de l'article est définir leurs origines et leurs perspectives, autre que leur caractère pratique et leur capacité d'influence. Ensuite, l'article analyse quelques questions sur leur importance et leur viabilité dans certains cas des violations des droits de l'homme.

* Investigador del Instituto de Investigaciones Jurídicas de la UNAM.

Anuario Mexicano de Derecho Internacional, vol. V, 2005, pp. 83-122 
SUMARIO: I. Introducción. II. La solución amistosa como un medio para resolver disputas en el derecho internacional de los derechos humanos. III. Panorama de la solución amistosa de peticiones individuales en los sistemas universal, europeo y africano de protección de los derechos humanos. IV. La solución amistosa de peticiones en el sistema interamericano de protección de los derechos humanos.

\section{INTRODUCCIÓN}

La solución amistosa de controversias entre Estados se encuentra entre los principales propósitos de la comunidad internacional. Esto es confirmado por el preámbulo y el artículo 33 de la Carta de las Naciones Unidas; en el primero se enfatiza dicho principio y en la carta se enlistan diversos procedimientos considerados como medios pacíficos de solución de conflictos, por ejemplo: la negociación, la investigación, la mediación, la conciliación, el arbitraje, el arreglo judicial y el recurso a organismos regionales.

Una manera de dar efecto al principio señalado ha sido incluir medios específicos y procedimientos como parte del contenido de los propios tratados internacionales, con el fin de resolver las controversias que sobre su aplicación y observancia pudieran surgir entre los Estados partes. Este es, al parecer, el camino seguido en asuntos de derechos humanos, en virtud de que varios de los tratados más relevantes de este tipo prevén mecanismos específicos con el fin de resolver peticiones interestatales e individuales sobre posibles violaciones a los derechos humanos, ambas consideradas como controversias internacionales en el derecho internacional contemporáneo. ${ }^{1}$

El procedimiento de peticiones interestatales (Estado vs. Estado), se inclina hacia el arreglo amistoso de los conflictos que pudieran surgir sobre aplicación y respeto de los derechos humanos, en armonía con el principio de arreglo amistoso de controversias. Sin embargo, tratándose del procedimiento para resolver peticiones individuales la situación parece ser distinta, pues mientras a nivel universal no se señala expresamente una fase de solución amistosa, en cambio, ésta sí es contemplada en

1 Véase Lante, Nii, The Settlement of International Disputes, The Contribution of Australia and New Zealand, La Haya, Martinus Nijhoff Publishers, 1998, pp. 10-11. 
sistemas regionales como el europeo y el interamericano. Por lo que se refiere al sistema africano, no contempla dicha fase, siguiendo el camino de los mecanismos universales, pero en la práctica se alienta y se lleva a cabo.

La solución amistosa en estos casos permite llegar a un arreglo negociado entre el Estado presuntamente responsable de una violación a derechos humanos y la supuesta víctima, bajo la supervisión de un órgano supranacional.

A primera vista, la posibilidad de lograr un arreglo amistoso en casos de violaciones a los derechos humanos parece incompatible con la naturaleza "no negociable" de este tipo de derechos, y también con el tipo de obligaciones jurídicas a cargo de los Estados en la materia. No obstante, el mecanismo ha adquirido una creciente importancia en la solución de casos de violaciones a los derechos humanos, cuando existe voluntad en el Estado y las víctimas para resolver anticipadamente un asunto antes de esperar a la tramitación completa del procedimiento y arribar a una condena internacional contra el Estado o, en ciertos casos, a una sentencia internacional.

Este ha sido un tema del que la doctrina no se ha ocupado abundantemente, de hecho, únicamente es abordado como parte de estudios más generales acerca de los sistemas internacionales de protección de los derechos humanos. Es por esto que en este trabajo pretendemos exponer los aspectos más sobresalientes de un tema con muchas aristas, así como definir su naturaleza, alcances, limitaciones y posibilidades futuras.

\section{LA SOLUCIÓN AMISTOSA COMO UN MEDIO PARA RESOLVER DISPUTAS EN EL DERECHO INTERNACIONAL DE LOS DERECHOS HUMANOS}

\section{El principio de solución pacifica de controversias en el derecho internacional}

La solución pacífica de controversias (SPC) es un principio dirigido a evitar el recurso estatal a la guerra y, en general, rechazar el uso de la 
fuerza como un medido de resolver disputas surgidas en las relaciones internacionales. ${ }^{2}$

La SPC está firmemente reconocida a nivel universal y regional. En el ámbito de la Organización de Naciones Unidas, el principio está implícito en el preámbulo de la carta $^{3}$ que da vida a la organización; se hace alusión expresa al mismo en varios preceptos (artículos 1.1, 2.3 y 52), y el capítulo VI está dedicado a regular específicamente la solución pacífica de controversias (artículos 33 a 38 ). ${ }^{4}$

Los preceptos de la Carta de la ONU en la materia han sido desarrollados a través de algunos instrumentos internacionales, como el Acta General Revisada para el Arreglo Pacífico de las Controversias Internacionales, de 1949; la Declaración sobre los Principios de Derecho Internacional referentes a las Relaciones de Amistad y a la Cooperación entre los Estados, de Conformidad con la Carta de las Naciones Unidas, de 1970; la Declaración de Manila sobre el Arreglo Pacífico de Controversias Internacionales, de 1982; y la Declaración sobre la Prevención y Remoción de Disputas y Situaciones que Pudieran Amenazar la Paz y la Seguridad Internacionales y sobre el Papel de las Naciones Unidas en este Campo: todos éstos han detallado y reafirmado la validez del principo de SPC. ${ }^{5}$

A nivel regional los esfuerzos en la materia no han sido menos relevantes, vale la pena mencionar que el principio de SPC se encuentra previsto en los artículos 23 a 26 de la Carta de la Organización de Estados Americanos, suscrita en Bogotá en 1948. Es más, dentro del marco de ésta organización, el 30 de abril de 1948 fue adoptado el Tratado Ameri-

2 Para un panorama del marco de la solución pacífica de controversias en el ámbito de la ONU, véase United Nations, Handbook on the Peaceful Settlement of Disputes between States, Nueva York, United Nations, 1992.

3 Firmada en San Francisco el 26 de junio de 1945, en vigor a partir del 24 de octubre de 1945. En el preámbulo de la carta se señala que los Estados partes decidieron "crear condiciones bajo las cuales puedan mantenerse la justicia y el respeto a las obligaciones emanadas de los tratados y de otras fuentes del derecho internacional", y al respecto, éstos acuerdan "asegurar, mediante la aceptación de principios y la adopción de métodos, que no se usará la fuerza armada sino en servicio del interés común".

4 Para un análisis detallado de cada uno de los medios de SPC entre Estados, previstos en la Carta de la ONU, véase United Nations, op. cit., nota 2, pp. 9-109; Lante, Nii, op. cit., nota 1, pp. 28-177.

5 Para un panorama completo de los documentos relevantes adoptados en el marco de la ONU y de las organizaciones regionales hasta 1992, véase United Nations, op. cit., nota 2, especialmente pp. 3 y 4 , y 83-97. 
cano de Soluciones Pacíficas, "Pacto de Bogotá", como un instrumento específico sobre el tema. ${ }^{6}$

En Europa, además de la Convención Europea para el Arreglo Pacífico de Controversias de 1957, resultan relevantes el Acta Final de la Conferencia de Helsinki sobre Seguridad y Cooperación en Europa (CSCE) de 1975, la Carta de París para una Nueva Europa de 1990, el Informe de la Reunión de Expertos de la CSCE sobre Arreglo Pacífico de Controversias de 1991, aprobado en La Valleta, y el Documento de Helsinki de $1992 .{ }^{7}$

Por lo que se refiere a la Organización de la Unidad Africana, sustituida recientemente por la Unión Africana (creado por documento constitutivo, suscrito en Togo el 11 de julio de 2000), el principio se encuentraba establecido en el artículo XIX de su documento constitutivo, y fue desarrollado posteriormente mediante el Protocolo del Cairo suscrito el 21 de julio de $1964 .{ }^{8}$ El documento de la actual Unión Africana consagra dicho principio en el artículo 4 (e).

Como puede observarse, la SPC es un principio profundamente arraigado en al ámbito internacional, y no resulta extraño que haya dejado sentir su influencia también en el campo del derecho internacional de los derechos humanos. En efecto, en el área de los derechos humanos los tratados universales y regionales no han sido la excepción al establecimiento de procedimientos para resolver pacíficamente controversias entre los Estados partes, máxime si se considera que este dipo de disputas puede derivar en situaciones que puedan poner en peligro la paz y la seguridad internacionales.

El procedimiento de comunicaciones interestatales, en algunos de los principales tratados universales y regionales, es el ejemplo más claro de la vigencia del principio de SPC en el derecho internacional de los derechos humanos. Adicionalmente, algunos tratados de este tipo contemplan procedimientos que permiten la presentación de quejas individuales contra un Estado, cuando éste infringe los derechos previstos en dicho tratado. ${ }^{9}$

6 Ibidem, p. 84.

7 Ibidem, p. 87.

8 Idem.

9 Debe puntualizarse que ambos procedimientos son comúnmente de carácter opcional, por lo que depende de los Estados ser o no parte en este tipo de mecanismos. 
De esta manera, es precisamente en este tipo de casos que se suscitan ciertos cuestionamientos, lo que podría ser razonablemente válido y justificable tratándose de desacuerdos entre Estados, puede que no lo sea en los casos en que se enfrente el Estado y una víctima de violaciones a los derechos humanos, especialmente en asuntos de naturaleza agravada.

\section{La naturaleza del procedimiento de solución amistosa} de peticiones de derechos humanos

La solución amistosa de peticiones de derechos humanos es una figura que pertenece a una categoría más amplia de medios para resolver disputas. De hecho, es considerada como un tipo de conciliación, la cual es uno de los medios universalmente aceptados para resolver controversias internacionales.

No es una tarea sencilla separar con precisión cada uno de los procedimientos para el arreglo de controversias, tales como la negociación, la investigación, la mediación, la conciliación, el arbitraje y el arreglo judicial. Sin embargo, la conciliación tiene algunos rasgos que la distinguen del resto de los mecanismos señalados. ${ }^{10}$

Algunos autores afirman que dicha figura combina las características de la investigación y de la mediación; ${ }^{11}$ de la primera de éstas porque es asunto esclarecido, y de la última porque se trata de acercar a las partes en disputa con el fin de alcanzar un acuerdo a través de propuestas de solución al asunto, que sean mutuamente aceptadas. ${ }^{12}$

La presencia de este tipo de solución alternativa, tratándose de peticiones interestatales, es ampliamente aceptada y recurrir a ella es un deber obligatorio para los Estados. No obstante, como ya se apuntó, el arreglo amistoso puede suscitar dudas acerca de su naturaleza y su pertinencia en los casos de controversias sobre derechos humanos entre un Estado y un individuo o grupos de individuos. De acuerdo con la opinión de César Sepúlveda, resulta difícil determinar si éste tipo de controversias pueden ser normalmente resueltas a través del uso de métodos

10 Véase Collier J. y Lowe V., The Settlement of Disputes in International Law, Institutions and Procedures, Nueva York, Oxford University Press, 1999, pp. 29-31; United Nations, op. cit., nota 2 , pp. 45-55.

11 Collier J. y Lowe V., op. cit., nota anterior, p. 29; ibidem, p. 45.

12 United Nations, op. cit., nota 2, pp. 45, 47. 
amistosos, o si dicho procedimiento sólo es adecuado para casos ciertos y específicos. ${ }^{13}$

Para el autor mencionado, la naturaleza de la solución amistosa no es clara ni en los instrumentos internacionales ni en la práctica de los organismos que conocen de ella, pues mientras que para algunos autores se trata de un método similar a los buenos oficios, para otros presenta mayores similitudes con la mediación.

Consideramos que la conciliación tiene las características que más se identifican con el estatus actual de la solución amistosa en los procedimientos internacionales de protección de los derechos humanos. El procedimiento permite al órgano conciliatorio acercarse a las partes, investigar los hechos, e incluso emitir algunas recomendaciones que las partes pueden o no aceptar. ${ }^{14}$

P. van Dijk y G. J. H. van Hoof señalan que el procedimiento de solución amistosa es una forma de conciliación, pero éste último es un término aplicable principalmente a los casos de controversias entre Estados. Por esto, dichos autores explican que el término "solución amistosa" fue escogido con el fin de abarcar tanto las quejas interestatales, como las individuales, ${ }^{15}$ lo cual confirma que éstas últimas tienen rasgos distintivos respecto de las controversias entre Estados.

En la práctica, debe tenerse en mente que en los asuntos de derechos humanos los órganos de conciliación son a su vez órganos de supervisión internacional, por lo que es casi imposible separar con claridad ambas funciones. El órgano de supervisión no sólo avanza la posibidad de solución amistosa, sino que aprueba y vigila la implementación del acuerdo alcanzado.

La solución amistosa, considerada como una etapa dentro del procedimiento de peticiones individuales, será el punto central de análisis en los apartados siguientes.

13 Sepúlveda, César, "El procedimiento de solución amistosa ante la Comisión Interamericana de Derechos Humanos", Inter-American Commission on Human Rights, Human Rights in the Americas, Homage to the Memory of Carlos A. Dunshee de Abranches, Washington, OEA, 1984, p. 242.

14 Ibidem, pp. 243 y 244.

15 Dijk, P. van y Hoof, G. J. H. van, Theory and Practice of the European Convention on Human Rigths, 2a. ed., Países Bajos, Kluwer Law and Taxation Publishers, 1990, p. 119. 


\section{PANORAMA DE LA SOLUCIÓN AMISTOSA DE PETICIONES INDIVIDUALES EN LOS SISTEMAS UNIVERSAL, EUROPEO Y AFRICANO DE PROTECCIÓN DE LOS DERECHOS HUMANOS}

\section{Aspectos sobresalientes de la solución amistosa de peticiones en el sistema universal}

De acuerdo con el estatus del principio de SPC en el derecho internacional, queda claro que en asuntos de derechos humanos los Estados también tienen el deber de resolver de manera pacífica cualquier disputa que pudiera surgir entre ellos.

Con relación a las controversias que pueden presentarse entre los Estados parte de los tratados de derechos humanos, algunos tratados prevén procedimientos opcionales para resolverlas. Ejemplo de lo anterior son la Convención Internacional sobre la Eliminación de todas las Formas de Discriminación Racial de 1965 (CEDR), el Pacto Internacional de Derechos Civiles y Políticos de 1966 (PIDCyP); la Convención sobre la Eliminación de Todas las Formas de Discriminación contra la Mujer de 1979 (CEDM); la Convención contra la Tortura y otros Tratos o Penas Crueles, Inhumanos o Degradantes de 1984 (CCT); la Convención Internacional contra el Apartheid en los Deportes de 1985; y la Convención Internacional sobre la Protección de los Derechos de todos los Trabajadores Migratorios y de sus Familiares de 1990 (CIPTM). No obstante, el procedimiento que se tramita ante el Comité sobre la Discriminación Racial no requiere de los Estados parte declaración adicional alguna a la ratificación, basta con ésta para que adquieran el deber de someter las controversias que surjan a las disposiciones de la convención sobre la materia. ${ }^{16}$

Por otro lado, entre los tratados de Naciones Unidas que establecen mecanismos para resolver peticiones individuales se encuentran la CEDR, ${ }^{17}$ el PIDCyP a través de su protocolo facultativo (PIDCyP-PF), ${ }^{18}$ la CCT, ${ }^{19}$ la CEDM a través de su protocolo facultativo (CEDM-PF) y la

16 Véase United Nations, op. cit., nota 2, pp. 147 y n. 583.

17 Adoptada por la Asamblea General de las Naciones Unidas el 7 de marzo de 1966, misma que entró en vigor el 4 de enero de 1969.

18 Adoptado por la Asamblea General de Naciones Unidas el 16 de diciembre de 1966, en vigor a partir del 23 de marzo de 1976.

19 Adoptada por la Asamblea General de Naciones Unidas el 10 de diciembre de 1984 y entró en vigor el 26 de junio de 1987. 
CIPTM. ${ }^{20}$ De hecho, un procedimiento del mismo tipo podría ser contemplado en el proyecto de protocolo al Pacto Internacional de Derechos Económicos, Sociales y Culturales (PIDESC). ${ }^{21}$

En el ámbito universal, todos los instrumentos internacionales mencionados tienen en común el establecimiento de un comité, integrado por un número determinado de expertos independientes, a cargo de la supervisión y evaluación del cumplimiento de los Estados a las disposiciones del tratado respectivo, y de atender y resolver las peticiones individuales e interestatales que se presenten.

No obstante que la incidencia práctica del procedimiento de comunicaciones interestatales es materialmente nula, ${ }^{22}$ lo importante es señalar que el mismo está dirigido definitivamente a la solución pacífica del asunto, lo que constituye su esencia y finalidad última, ya sea que se deje exclusivamente a los Estados la oportunidad de resolverlo o que se dé intervención, en mayor o menor grado, al comité respectivo.

En estos casos, el comité que corresponda debe jugar un papel activo con el fin de proponer el mayor número de opciones posibles que sean necesarias para alcanzar un acuerdo entre las partes de la disputa. Además de esto, dicho órgano debe supervisar que cualquier acuerdo alcanzado esté acorde con las disposiciones de derechos humanos del tratado en cuestión; de otra forma, el comité estaría apoyando una situación contraria a los derechos humanos, cuyo respeto está obligado jurídicamente a supervisar.

Por lo que se refiere a los procedimientos de tramitación y solución de peticiones individuales, no parecen tener un énfasis especial en el arreglo amistoso del asunto $\mathrm{y}$, de hecho, ninguno de los tratados mencio-

20 El Protocolo de la CEDM fue adoptado por la Asamblea General de Naciones Unidas el 6 de octubre de 1999 y entró en vigor el 22 de diciembre de 2000. La MWC fue adoptada por la Asamblea General de Naciones Unidas el 18 de diciembre de 1990 y se encuentra en vigor desde julio de 2003.

21 Véase Cançado Trindade, Antonio Augusto, "A Regra do Esgotamento dos Recursos Internos Revisitada: Desenvolvimentos Jurisprudenciais Recentes no Âmbito da Proteçao Internacional dos Direitos Humanos", en varios autores, Corte Interamericana de Derechos Humanos, Liber Amicorum Héctor Fix-Zamudio, San José, Corte Interamericana de Derechos Humanos-Unión Europea, 1998.

22 Para un análisis del procedimiento ante los comités previstos en el PIDCyP y en la CCT, véase respectivamente Boulesbaa, A., The U. N. Convention on Torture and the Prospects for Enforcement, Países Bajos, Martin Nijhoff Publishers, 1999, pp. 107-188 y pp. 277-293; Barkhuysen, T. et al., The Execution of Strasbourg and Geneva Human Rights Decisions in the National Legal Order, Países Bajos, Martin Nijhoff Publishers, 1999, pp. 101-112. 
nados contiene disposiciones acerca de la posibilidad de lograr un arreglo amistoso entre el Estado al que se imputa la violación y el quejoso o la víctima de ésta. Las reglas de procedimiento de cada uno de los comités mencionados tampoco hacen referencia a dicha posibilidad. ${ }^{23}$

Esto no significa que la solución amistosa en casos de peticiones individuales esté prohíbida. La posibilidad de un arreglo amistoso de naturaleza "no oficial" no es sólo de carácter teórico, ${ }^{24}$ sino que es una opción cierta que debe tener presente el comité respectivo, por sí o a través del peticionario o el Estado, con el propósito de supervisar que el acuerdo logrado sea compatible con las obligaciones internacionales del propio Estado en materia de derechos humanos y que no se ha tomado ventaja de la víctima de las violaciones.

De no cumplirse estos extremos, el comité está en aptitud de continuar con el examen de la cuestión y emitir en su momento las conclusiones y recomendaciones pertinentes al Estado, incluyendo la evaluación del acuerdo supuestamente alcanzado.

Como corolario se puede afirmar que a nivel universal los tratados de derechos humanos que prevén una fase de arreglo amistoso como parte del procedimiento de quejas interestatales, están en armonía con el pricipio de SPC. Por otro lado, dicha fase no se encuentra contemplada expresamente por lo que a las peticiones individuales se refiere; no obstante, subsiste la posibilidad real de arribar a un arreglo amistoso en estos casos, dado lo cual, el comité respectivo debe determinar cuidadosamente su compatibilidad con los estándares vigentes de derechos humanos antes de proceder a refrendarlo.

\section{Aspectos sobresalientes de la solución amistosa de peticiones en el sistema europeo de protección de los derechos humanos}

El sistema europeo de protección de los derechos humanos ha funcionado primordialmente sobre la base de la Convención para la Protección de los Derechos Humanos y las Libertades Fundamentales (CEDH), adoptada en Roma el 11 de noviembre de 1950 y en vigor a partir del 3

23 Estos pueden consultarse en el documento HRI/GEN/3, de 6 de junio de 2001, elaborado por la secretario general de la ONU.

24 Véase algunos de los casos a los que se hace referencia en Barkhuysen T. et al., op. cit., nota 22 , p. 111. 
de septiembre de $1953 .{ }^{25}$ Dicha convención ha sido modificada en lo sustantivo y en el aspecto procedimental mediante la adopción de protocolos, siendo el más trascendente hasta hoy el número 11, en vigor a partir de noviembre de 1998, por el que se determinó el establecimiento de una Corte Permanente de Derechos Humanos en sustitución del sistema previo que tenía por órganos centrales a la comisión y a la corte europeas de derechos humanos.

Si bien en el sistema europeo sí han tenido lugar peticiones interestatales, éstas han constituido un número ínfimo con relación al de peticiones individuales. El Informe de Actividades y Estadísticas de 1997 de la Comisión Europea de Derechos Humanos reflejaba desde 1955 un total de 39,047 peticiones. Este número contrasta drásticamente con el total de tan sólo 13 peticiones interestatales presentadas en el mismo periodo.

Con relación al tema específico de la solución amistosa de peticiones individuales, antes y después de la entrada en vigor del Protocolo número $11,{ }^{26}$ ésta ha jugado un papel de especial relevancia. En efecto, la solución amistosa relativa a las peticiones individuales ha sido un procedimiento previsto desde la adopción de la CEDH. ${ }^{27}$ De hecho, se ha señalado que el proceso de solución amistosa es posiblemente la pieza central de la convención. ${ }^{28}$

S. Davidson cita la opinión de sir Humphrey Waldock, quien fungió en su momento como presidente de la Comisión Europea de Derechos Humanos:

25 Véase Zwart, T., The Admissibility of Human Rights Petitions: The Case Law of the European Commission of Human Rights and the Human Rights Committee, Países Bajos, Martinus Nijhoff Publishers, 1994; Gominen D. et al., Law and Practice of the European Convention on Human Rights and the European Social Charter, Alemania, Council of Europe Publishing, 1996; Harris, D. J. et al., Law of the European Convention on Human Rights, Londres, Butterworths, 1999.

26 El anterior artículo 28 corresponde en su contenido al 38 del texto derivado del Protocolo 11.

27 Véase Dijk, P. van y Hoof, G. J. H. van, op.cit., nota 15, pp. 118-131; Clements, L., European Human Rights: Taking a Case under The Convention, Londres, Sweet y Maxwell, 1994, pp. 55-59. De acuerdo con el artículo 28.1.b de la CEDH, una vez admitida una petición, la comisión tenía que "ponerse a disposición de las partes involucradas con miras a asegurar un arreglo amistoso del asunto sobre la base del respeto a los derechos humanos definidos en esta convención". En armonía con lo anterior, el artículo 53 del reglamento de la Comisión Europea de Derechos Humanos de 1993, una vez que ésta había decidido admitir una petición, debía determinar el procedimiento que había de seguirse para tramitar la decisión con miras a lograr el arreglo amistoso de la misma.

28 Clements, L., op. cit., nota 27, p. 55. 
Los redactores de la convención acertaron en hacer del arreglo amistoso el remedio central dentro de la estructura de ésta. Él señaló: la investigación de las deficiencias de un Estado con relación a los derechos humanos es una forma muy delicada de intervención en sus asuntos internos. La obligación primaria de la comisión es conducir negociaciones confidenciales con las partes e intentar enmendar cualquier violación a los derechos humanos que pudiera haber ocurrido. No fue establecida primordialmente con el propósito de poner a los Estados contra la pared y provocar condenas en contra de éstos.

Claramente, la comisión debe situarse como una via intermedia y no debe parecer que favorece a alguna de las partes a expensas de la otra, aunque pudiera sentirse que la función conciliatoria permite a los Estados escabullirse ligeramente en algunas ocasiones. ${ }^{29}$

Esta opinión es útil para trazar las raíces y la naturaleza de la solución amistosa respecto de peticiones individuales, misma que ha tenido una incidencia destacable. El Informe de Actividades y Estadísticas de 1997 de la Comisión Europea de Derechos Humanos muestra la incidencia tanto de informes de fondo, como de solución amistosa enviados al Comité de Ministros de 1955 a 1997. Mientras los informes de fondo ascendieron a un total de 2,792 , los relativos a soluciones amistosas llegaron a 369 , esto es, alrededor del $13 \%$.

Clements afirma que "en los primeros 26 años de la convención, las soluciones amistosas no eran frecuentes. El hecho de que ahora se presenten con mayor frecuencia se debe sobre todo a los precedentes derivados de las decisiones e informes de la comisión y a los fallos de la corte. El desarrollo de una extensa jurisprudencia ha situado a las partes en una posición mucho mejor para predecir el posible resultado de un caso ante la corte". ${ }^{30}$

Las cifras más recientes confirman la importancia que este tipo de soluciones ha adquirido bajo el nuevo esquema derivado de la entrada en vigor del Protocolo 11; durante 1999, la Corte Europea de Derechos Humanos emitió 177 fallos de fondo, 42 de los cuales tuvieron por objeto dar de baja a un número idéntico de peticiones de la lista de casos. Esta última cifra incluye 37 soluciones amistosas, tres arreglos y dos casos adicionales dados de baja sin señalarse la razón específica de esto. 
En 1999, hubo 177 fallos y 42 determinaciones sobre soluciones amistosas; en el 2000, frente a 446 sentencias de fondo, hubo 230 soluciones amistosas; en el 2001, hubo 725 sentencias de fondo y 151 soluciones amistosas; en el 2002, se dictaron 665 sentencias de fondo y 151 soluciones amistosas; finalmente, en el 2003 hubo un total de 548 fallos de fondo y 128 soluciones amistosas. Como puede apreciarse, con relación únicamente a los fallos de fondo - haya sido o no encontrado responsable el Estado - las soluciones amistosas representan una cifra similar de alrededor de $20 \%$ de los casos decididos.

En la práctica, el procedimiento está caracterizado por la confidencialidad e informalidad de las negociaciones que invitan a las partes a externar sus posiciones de una forma más franca y libre con miras a un arreglo amistoso. Varios autore ${ }^{31}$ afirman que las partes estaban más inclinadas a aceptar la posibilidad de un arreglo amistoso, en los casos en que la comisión decidía hacer uso de la facultad prevista en el artículo 55 de sus reglamentos de 1993. Esta disposición autorizaba a la comisión a deliberar con miras a lograr una opinión provisional sobre el fondo del asunto.

La opinión provisional alcanzada, notificada oral y confidencialmente a las partes, podría por supuesto estimular la voluntad de éstas para lograr un arreglo. ${ }^{32} \mathrm{La}$ facultad de producir y comunicar una opinión provisional de este tipo, al parecer ha prevalecido bajo el nuevo esquema derivado del Protocolo 11.33

La comisión, y ahora la nueva corte, tenía facultades para acercarse a las partes de manera formal o informal, de forma separada o conjuntamente, según sea el camino más favorable a la posibilidad de alcanzar un arreglo amistoso. ${ }^{34}$

Dos factores adicionales contribuyen a facilitar un arreglo amistoso entre las partes: uno de éstos es la flexibilidad y el carácter informal del procedimiento, el cual ayuda a crear una atmósfera en la que es más fácil para las partes alcanzar un compromiso. En este contexto, juega una parte importante el hecho de que la consideración de la petición por la comi-

31 Harris, D. J. et al., op. cit., nota 25, p. 600; Dijk, P. van y Hoof, G. J. H. van, op. cit., nota 15, pp. $118,121$.

32 Dijk, P. van y Hoof, G. J. H. van, op. cit., nota 15, p. 121.

33 Clements L.; Mole N. y Simmons A., European Human Rights: Taking a Case Under the Convention, 2a. ed., Londres, Sweet y Maxwell, 1999, p. 76.

34 Dijk, P. van y Hoof, G. J. H. van, op. cit., nota 15, p. 121. 
sión tiene lugar a puerta cerrada. ${ }^{35}$ Este factor es también aplicable en el procedimiento vigente ante la corte.

El segundo factor consiste en que las opiniones, ofrecimientos y posiciones de las partes durante la fase de solución amistosa, no eran tomadas en cuenta a la hora de decidir sobre el fondo del asunto. Aún en la etapa ante la corte se decía que las partes no son libres de divulgar en sus comunicaciones orales y escritas los ofrecimientos hechos o las posiciones adoptadas durante las discusiones sobre el acuerdo amistoso. ${ }^{36}$

Actualmente, en atención al artículo 38.2 de la $\mathrm{CEDH}$, los procedimientos que tienen lugar durante la etapa de solución amistosa deben ser confidenciales. Cuando las negociaciones finalizan exitosamente, el acuerdo alcanzado es usualmente formalizado a través de un intercambio de cartas entre las partes. Posteriormente, las partes deben dedicar sus esfuerzos al cumplimiento de los términos acordados.

Fuera de la ausencia de rígidas formalidades durante las negociaciones de un arreglo amistoso, el artículo 28.1.b de la CEDH impuso un requisito sustantivo que debía satisfacer todo acuerdo amistoso: estar acorde con el respeto a los derechos humanos definidos en la Convención Europea. De acuerdo con el texto del nuevo artículo 38.1.b, el acuerdo amistoso debe estar, además, conforme con los diversos protocolos de la convención (se entiende que hace referencia a los de carácter sustantivo).

Debe puntualizarse que usualmente el acuerdo amistoso incluye una cláusula a través de la cual el Estado rechaza la reconocimiento de su responsabilidad, y que sus compromisos están basados en su "buena fe"; también se incluye por parte del peticionario su renuncia a plantear cualquier tipo de queja o procedimiento posterior sobre la materia del asunto. Esto no es más que la evidencia de lo difícil que resulta, aún en estos casos, que el Estado acepte plenamente su responsabilidad por los hechos acontecidos. ${ }^{37}$

Los Estados por lo regular están pendientes de no ir más allá de lo estrictamente necesario en los compromisos que adquieren, especialmente por lo que se refiere a aquellos que dependan de la decisión de los órganos jurisdiccionales internos o de la adopción de disposiciones norma-

35 Ibidem, p. 119.

36 Harris, D. J. et al., op. cit., nota 25, p. 602.

37 Idem. Véase también Farran, S., The UK Before the European Court of Human Rights, Case Law \& Commentary, Blackstone Press Limited, 1996, pp. 384-386. 
tivas generales. ${ }^{38}$ No obstante lo anterior, es el Estado in toto el que debe responder por la violación cometida, no sólo una de las ramas del gobierno en turno.

P. van Dijk y G. J. H. van Hoof señalan que en algunos casos se aprecia que los gobiernos están tentados a ofrecer únicamente una suma de dinero para dar el caso por terminado, como si éstos desearan comprar la violación, mientras el origen de ésta, por ejemplo en la forma de una disposición legislativa o de alguna práctica administrativa que conflictúa con la convención, continuaría existiendo. ${ }^{39}$

Una vez llegado a un acuerdo bajo el esquema anterior al vigente Protocolo 11, afirma Clements que el arreglo amistoso negociado durante el procedimiento ante la comisión no era supervisado por el Comité de Ministros, más aún, en la convención no estaba previsto mecanismo de supervisión alguno para la implementación de los acuerdos. ${ }^{40}$

Sin embargo, algunos autores afirman que, dejando de lado algunos retrasos burocráticos, el Estado acostumbra a cumplir con los compromisos adquiridos. ${ }^{41}$

El arreglo amistoso, se ha opinado, también podía tener lugar en la corte o ante el Comité de Ministros (en aquellos casos que no eran llevados por la comisión ante la primera). ${ }^{42}$

Resulta claro el papel central que la solución amistosa de peticiones individuales ha desempeñado en la práctica del sistema europeo de protección de los derechos humanos, gracias a que ha sido una figura prevista y regulada expresamente desde los inicios del sistema hasta la actualidad. Al ser el cauce por el cual son resueltos aproximadamente la quinta parte de los casos, se avisora una incidencia creciente, inclusive es una opción que debe ser alentada con mayor intensidad por la propia corte, con el fin de aliviar en algún grado la difícil situación del enorme número de asuntos que impiden su funcionamiento ágil.

38 Harris, D. J. et al., op. cit., nota 25, p. 601.

39 Dijk, P. van y Hoof, G. J. H. van, op. cit., nota 15, p. 120.

40 Harris, D. J. et al., op. cit., nota 25, p. 602.

41 Ibidem, p. 602; Clements, L., op. cit., nota 27, p. 57.

42 Clements, L., op. cit., nota 27, p. 92. 


\section{Aspectos sobresalientes de la solución amistosa de peticiones}

en el sistema africano de protección de los derechos humanos

El funcionamiento del sistema africano de protección de los derechos humanos descansa en lo sustantivo en la Carta Africana de Derechos Humanos y de los Pueblos (CADHP), adoptada en Banjul el 27 de junio de 1981 y en vigor a partir del 21 de octubre de 1986; y desde el punto de vista institucional en una comisión, ${ }^{43}$ y más recientemente también en una Corte Africana prevista en un Protocolo Opcional a la Carta Africana en vigor a partir del 25 de enero de 2004.

De forma similar a los mecanismos que operan en los sistemas universales y regionales de derechos humanos, el sistema africano prevé procedimientos para tramitar peticiones interestatales e individuales. El procedimiento para resolver peticiones interestatales es en realidad una amalgama de rasgos distintivos de los sistemas universal y regionales.

Al igual que los sistemas descritos en el presente trabajo, el procedimiento de quejas interestatales prevé la posibilidad de lograr una solución amistosa entre las partes de la controversia. ${ }^{44}$

Un Estado que decidiera dirigir una comunicación contra otro Estado por violaciones a los derechos humanos, puede hacerlo a éste, dando únicamente noticia de esto a la Comisión Africana, o puede dirigirse a ésta directamente. ${ }^{45}$ En la primera hipótesis, la convención establece que el asunto debe ser resuelto a satisfacción de los Estados involucrados mediante negociaciones bilaterales o cualquier otro procedimiento pacífico; una vez que esta etapa ha sido agotada, si no ha tenido éxito, cualquiera de los Estados está facultado para presentar el caso ante la comisión. ${ }^{46}$

El papel que la comisión desempeña es principalmente conciliatorio y por esto debe intentar por todos los medios posibles lograr una solución amistosa basada en el respeto a los derechos humanos y de los pueblos. ${ }^{47}$

Por lo que se refiere al procedimiento de peticiones individuales en el marco de la CADHP, si bien contiene disposiciones de similar contenido a otros sistemas de peticiones, posee marcadas características distin- 
tivas. Entre éstas últimas se encuentra la posibilidad de presentar quejas sobre violaciones a los derechos económicos, sociales y culturales previstos en la CADHP, y de casos que puedan revelar la existencia de una serie de violaciones graves o masivas a los derechos humanos. ${ }^{48}$

Bajo el título de "otras comunicaciones" la CADHP establece que una queja puede ser considerada si el peticionario cumple con algunos requsitos formales y sustantivos, entre los que se encuentran el agotamiento de los recursos internos, la presentación en tiempo y que el asunto no esté siendo considerado por otros mecanismos de arreglo. ${ }^{49}$ Además, queda a la decisión de la comisión cuáles comunicaciones serán consideradas y cuáles no. ${ }^{50}$

Sólo a partir del Séptimo Informe Anual (1994) sobre las actividades de la comisión, ésta ha incluido un resumen de los casos decididos en materia de peticiones individuales. ${ }^{51} \mathrm{Ni}$ el Reglamento de la Comisión de 1995 ni tampoco el adoptado en 1998 son de mucha ayuda para esclarecer el funcionamiento práctico del procedimiento. Sin embargo, lo que es claro es que no está expresamente prevista una fase de solución amistosa en la consideración de peticiones distintas a las interestatales. ${ }^{52}$

No obstante lo anterior, la comisión ha comenzado a impulsar la solución amistosa de peticiones individuales, lo que lleva a U. Oji Umozurike a afirmar que la fuerza de la comisión, como se estipula actualmente en la carta, descansa en el arreglo amistoso. ${ }^{53}$

E. A. Ankumah señala que "de la letra y espíritu de la carta es claro que la comisión puede hacer intentos por lograr un acuerdo amistoso al mismo tiempo que lleva a cabo su investigación y elabora sus conclusiones con respecto al fondo del asunto". ${ }^{54}$

48 CADHP, artículo 58.

49 CADHP, artículo 56. Véase Ankumah, E. A., The African Commission on Human and Peoples Rights, Practice and Procedures, Países Bajos, Martinus Nijhoff Publishers, 1996, pp. 51-77.

50 CADHP, artículo 55.

51 Véase Umozurike, U. Oji, The African Charter on Human and Peoples Rights, Países Bajos, Martinus Nijhoff Publishers, 1997, p. 79. Véase también African Commission on Human and Peoples Rights. Decisions of the African Commission on Human and Peoples Rights (1986-1997) pursuant to Article 55 of the African Charter on Human and Peoples' Rights. Law Reports of the African Commission, series A., vol. 1. CADHP/LR/A/1, Banjul, 1997.

52 Véase Ankumah, E. A., op. cit., nota 49, p. 74.

53 Véase Umozurike, U. Oji, op. cit., nota 51, p. 79. Este autor afirma "La fuerza de la comisión reside en la solución amistosa, en virtud de que su poder de criticar las violaciones a derechos humanos se ve afectado por el requisito de confidencialidad y se ve retardado por procedimiento que exige informar primero a la Asamblea de Jefes de Estado". Ibidem, p. 83.

54 Véase Ankumah, E. A., op. cit., nota 49, p. 74. 
La comisión ha establecido en cierto número de casos que "el principal objetivo del procedimiento de comunicaciones ante la comisión es iniciar un posible diálogo que resulte en una solución amistosa entre el quejoso y el Estado involucrado, el cual remedie el perjuicio motivo de la queja. Un prerrequisito para solucionar amistosamente las violaciones a la carta es la buena fe de las partes involucradas, incluyendo su voluntad de participar en un diálogo". 55

De 1986 a 1997, los casos en que se ha logrado una solución amistosa incluye uno con base en la violación por prisión ilegal (11/8 Henry Kalenga vs Zambia); ${ }^{56}$ uno sobre irregularidades electorales (44/90 People's Democratic Organisation for Independence and Socialism vs The Gambia); ${ }^{57}$ uno sobre problemas concernientes a prisioneros políticos (16/88, 17/88, 18/88 Comité Culturel pour la Démocratie au Bénin, Badjogoume Hilaire, El Hadj Boubacar Diawara vs Benin);58 y uno en el cual la solución estaba aún pendiente pero bajo el esquema de arreglo amistoso (71/92 Rencontre Africaine pour la Defense des Droits de l'Homme vs Zambia). ${ }^{59}$

En los informes anuales de actividades décimo primero y décimo segundo, que cubren el perido de 1997 a 1999, no fueron reportadas soluciones amistosas alcanzadas. Sin embargo, en los subsecuentes informes anuales hasta el más reciente que abarca las actividades correspondientes al 2003 (décimo sexto), se observa una incidencia cada vez mayor de soluciones amistosas de peticiones individuales. Esto permite avisorar que este tipo de arreglos se perfila como una opción atractiva a las víctimas y a los propios Estados, apoyada y alentada por la propia Comisión Africana y que posiblemente también tendrá cabida en el procedimiento ante la Corte Africana, una vez en funciones.

55 Véase las consideraciones de fondo de la comisión en los casos 27/89, 46/91, 49/91, 99/93, 59/91, 64/92, 68/92, 78/92, publicados en el documento African Commission on Human and Peoples Rights, Decisions of the African Commission on Human and Peoples Rights (1986-1997) pursuant to Article 55 of the African Charter on Human and Peoples' Rights. Law Reports of the African Commission, Series A. Volume 1. ACHPR/LR/A/1, Banjul, 1997.

56 Ibidem, pp. 7 y 8 .

57 Ibidem, pp. 38-42.

58 Ibidem, pp. 11-15.

59 Ibidem, pp.77-82. 


\section{LA SOLUCIÓN AMISTOSA DE PETICIONES \\ EN EL SISTEMA INTERAMERICANO DE PROTECCIÓN \\ DE LOS DERECHOS HUMANOS}

\section{Introducción}

El funcionamiento del sistema interamericano de protección de los derechos humanos descansa institucionalmente en una comisión y una corte de derechos humanos. ${ }^{60}$ La comisión supervisa el cumplimiento por parte de los Estados de las disposiciones de la Declaración Americana de Derechos y Deberes del Hombre (DADDH), y básicamente de la Convención Americana sobre Derechos Humanos $(\mathrm{CADH})^{61}$ para aquellos Estados que la han ratificado, además de otros tratados interamericanos. ${ }^{62}$

La Comisión Interamericana de Derechos Humanos (CIDH) fue establecida en $1959,{ }^{63}$ y algunos años después, en 1965, fue facultada para tramitar peticiones individuales. ${ }^{64}$

La CIDH era el único órgano de supervisión del sistema desde su creación hasta 1978 en que entró en vigor la CADH, adoptada en 1969, que estableció como órgano adicional la Corte Interamericana de Derechos Humanos. La CADH prevé mecanismos para tramitar peticiones tanto interestatales, como individuales.

Debe señalarse que el marco institucional del sistema está inspirado en el sistema europeo, el cual comenzó su funcionamiento cerca de 25 años antes. Además de lo anterior, antes de la entrada en vigor del Proto-

60 Véase los artículos 36 y 53 de la CADH.

61 La Declaración Americana de los Derechos y Deberes del Hombre, adoptada en Bogotá el 2 de mayo de 1948. La Convención Americana sobre Derechos Humanos fue adoptada en San José el 22 de noviembre de 1969, en vigor a partir del 18 de julio de 1978.

62 Hay que agregar también en la actualidad a la Convención Interamericana para Prevenir y Sancionar la Tortura (artículo 8) y a la Convención Interamericana sobre Desaparición Forzada de Personas (artículos XIII y XIV); también admiten la posibilidad de que la comisión y la corte ejerzan sus atribuciones sobre peticiones individuales planteadas en el marco de éstas últimas. A éstas hay que sumar la posibilidad de plantear quejas conforme al Protocolo Adicional a la Convención Americana sobre Derechos Humanos en Materia de Derechos Económicos, Sociales y Culturales (artículo 19.6, relacionado con los artículos 8 y 13) y a la Convención Interamericana para Prevenir, Sancionar y Erradicar la Violencia contra la Mujer, "Convención de Belem do Para" (artículo 12).

63 Para consultar la historia, antecedentes políticos y el funcionamiento de la CIDH hasta 1968, véase Vasak, K., La Commission Interamericaine des Droits de L'Homme, París, Libraire Générale de Droit et de Jurisprudence, 1968, pp. 1-81.

64 Véase Buergenthal T. et. al., La protección de los derechos humanos en las Américas, Madrid, Instituto Interamericano de Derechos Humanos-Editorial Civitas, 1990, pp. 37 y 38. 
colo 11 que modificó sustancialmente el sistema europeo de protección de los derechos humanos, ambos sistemas compartían una estructura institucional similar para tramitar peticiones, aunque con marcadas características distintivas, sobre todo en el tema de integración de los órganos, y de decisiones de fondo y supervisión de fallos por el Comité de Ministros europeo.

Las normas que regulan la tramitación de peticiones individuales en el sistema interamericano varían dependiendo de si el Estado correspondiente ha ratificado o no la $\mathrm{CADH}$. Para aquellos Estados partes de ésta, el marco central de actuación lo constituye la propia Convención Americana, que establece las reglas básicas de procedimiento para el trámite de peticiones. ${ }^{65}$ Respecto al resto de los Estados del continente las peticiones interpuestas deben estar fundadas en alguno de los derechos previstos en la DADDH (de conformidad con el Estatuto, artículo 20, y el Reglamento de la $\mathrm{CIDH}$, artículos 49 y 50), el procedimiento en ambos esquemas es similar en casi todas sus fases.

A diferencia del procedimiento basado en la Convención Europea, las quejas interestatales en el sistema interamericano requieren de la previa aceptación de los Estados a la competencia de la comisión, para que ésta pueda tramitarlas. Respecto del procedimiento de quejas individuales, los Estados no tiene que hacer tal declaración; sin embargo, para que los casos puedan ser presentados por algún Estado parte de la CADH o por la comisión ante la Corte Interamericana, debe existir una declaración de aceptación de la competencia contenciosa de ésta por parte del Estado al que se imputa la violación. ${ }^{66}$

La fase de solución amistosa es parte del procedimiento de peticiones interestatales e individuales en el marco de la $\mathrm{CADH}$, pero no está expresamente contemplada en el caso de peticiones presentadas con base en el esquema de la DADDH.

\section{Antecedentes y evolución del procedimiento de solución} amistosa de peticiones

De acuerdo con César Sepúlveda, quien por cerca de 20 años fungió como comisionado integrante de la $\mathrm{CIDH}$, tanto la Convención Europea 
como el Pacto Internacional de Derechos Civiles y Políticos influenciaron la introducción del procedimiento de solución amistosa en la CADH. ${ }^{67}$

El artículo 48.1.f de la CADH señala textualmente que la comisión: "se pondrá a disposición de las partes interesadas, a fin de llegar a una solución amistosa del asunto fundada en el respeto a los derechos humanos reconocidos en esta convención".

Esta disposición es casi idéntica a la prevista en el artículo 28.1.b de la Convención Europea de Derechos Humanos ${ }^{68}$ (actuamente artículo 38.1.b del nuevo texto derivado del Protocolo 11).

No obstante lo anterior, la característica distintiva del procedimiento desde su introducción en la $\mathrm{CADH}$ ha sido su falta de utilización y la carencia de reglas claras y detalladas. ${ }^{69}$ De hecho, la forma en que opera el procedimiento está basada por completo en la experiencia práctica adquirida paulatinamente por la $\mathrm{CIDH}$.

César Sepúlveda afirma que el primer intento de lograr un arreglo amistoso, aunque infructuoso, ocurrió en 1981 en un caso contra Perú, cuyo gobierno había expropiado algunos periódicos. La propuesta de lograr un acuerdo surgió del gobierno en el poder, que decidió resolver por sí mismo el asunto supuestamente a favor de las víctimas. La CIDH dirigió propuestas de este tipo de solución en tres distintos casos, pero en todos ellos el arreglo no tuvo éxito. ${ }^{70}$

Uno de los casos más conocidos en los cuales la comisión tuvo la oportunidad de desarrollar sus atribuciones con respecto a la solución amistosa fue el caso de los miskitos. Este asunto se originó por diversas violaciones a los derechos humanos cometidas en 1981 por el gobierno

67 Sepúlveda, César, op. cit., nota 13, p. 242.

68 Dicho precepto señalaba, en su parte conducente, que la Comisión Europea tenía que "ponerse a disposición de las partes involucradas con miras a asegurar un arreglo amistoso del asunto sobre la base del respeto a los derechos humanos definidos en esta convención". En armonía con lo anterior, el artículo 53 del reglamento de la Comisión Europea de Derechos Humanos de 1993, una vez que la comisión había decidido admitir una petición, debía determinar el procedimiento que habría de seguirse para tramitar la decisión con miras a lograr el arreglo amistoso de la misma.

69 Sepúlveda, César, op.cit., nota 13, p. 242; véase también Aguilar, Andrés, "El procedimiento que debe aplicar la $\mathrm{CIDH}$ en el examen de las peticiones o comunicaciones individuales sobre presuntas violaciones de derechos humanos", en Inter-American Commission on Human Rights, Human Rights in the Americas, Homage to the Memory of Carlos A. Dunshee de Abranches, Washington, OEA, 1984, p. 213.

70 Sepúlveda, César, op.cit., nota 13, p. 244. 
de Nicaragua contra algunas personas de origen miskito. El caso involucraba transgresiones a diversos derechos humanos, tales como: afectaciones al derecho de libertad personal, a la integrídad, al debido proceso legal, a la libertad de movimiento y de residencia, y a los derechos de propiedad. Además, la complejidad del caso se incrementó debido a los problemas históricos y sociales profundamente enraizados que lo rodeaban. ${ }^{71}$

La invitación de la CIDH para alcanzar un arreglo amistoso fue aceptada por las partes, pero después de cerca de dos años de haber sido implementados importantes pasos para resolver el asunto bajo este esquema, algunos problemas llevaron a la comisión a decidir que no había condiciones para continuar el procedimiento de solución amistosa. ${ }^{72}$

La CIDH señaló en su decisión sobre el procedimiento de solución amistosa, que entre las razones para darlo por terminado se encontraban la imposibilidad de lograr un acuerdo acerca de la representación legítima de la comunidad de los miskitos, y también del mantenimiento de pláticas pacíficas entre las partes; además, la $\mathrm{CIDH}$ reconoció expresamente que entre los obstáculos que impidieron llegar a un arreglo amistoso se encontraban circunstancias fuera del control del gobierno de Nicaragua. ${ }^{73}$ Fuera de que el arreglo amistoso no pudo lograrse en este caso, la $\mathrm{CIDH}$ definitivamente enriqueció su propia experiencia con respecto a este tipo de procedimientos.

Posteriormente, la CIDH publicó en 1984 su informe sobre el fondo, en el cual declaró la responsabilidad del gobierno nicaragüense por las violaciones a derechos humanos en contra de población nicaragüense de origen miskito y emitió las recomendaciones correspondientes. ${ }^{74}$

71 Véase el Informe sobre la Situación de los Derechos Humanos de un Sector de la Población Nicaragüense de Origen Miskito (OEA/Ser.L/V/II.62, doc. 26, 16 de mayo 1984). Para un análisis del caso, véase Sepúlveda, César, op. cit., nota 13, pp. 242-246; véase también Méndez, Juan, "La participación de la Comisión Interamericana de Derechos Humanos en los conflictos entre los miskitos y el gobierno de Nicaragua", en Inter-American Commission on Human Rights, Human Rights in the Americas, Homage to the Memory of Carlos A. Dunshee de Abranches, Washington, OEA, 1984, pp. 306-318.

72 Véase el Informe sobre la Situación de los Derechos Humanos de un Sector de la Población Nicaragüense de Origen Miskito.

73 Véase el documento Resolución sobre el Procedimiento de Solución Amistosa sobre la Situación de los Derechos Humanos de un Sector de la Población Nicaragüense de Origen Miskito (OEA/Ser.L/V/II.62, doc. 26, 16 de mayo 1984).

74 Idem. 
Para Christina Cerna, la prolongada abstención de la CIDH para asumir oficialmente su rol en la solución amistosa de casos se debió a los siguientes factores: primero, la comisión, habiendo sido creada en 1959, no había completado su plena adaptación a las nuevas reglas impuestas por la entrada en vigor de la CADH en 1978; segundo, el tipo de violaciones documentadas y reportadas por la CIDH eran por lo regular de tal naturaleza que parecían incompatibles con arreglo amistoso alguno; por último, ningún procedimiento de solución amistosa había sido formalmente puesto en práctica antes de la entrada en vigor de la CADH. ${ }^{75}$

Las disposiciones de la CADH sobre la solución amistosa permanecieron sin ser detalladas hasta la aprobación del Reglamento de la CIDH de 1980. Sin embargo, éste resultó insuficiente para colmar los vacíos en la materia. ${ }^{76}$ De hecho, algunas propuestas para mejorar el procedimiento de solución amistosa deben mucho de su inspiración a la experiencia adquirida gracias al caso de los miskitos. ${ }^{77}$

Las modificaciones realizadas al mencionado Reglamento de la CIDH en 1985 y 1987 dieron al procedimiento de solución amistosa las bases de su tramitación. ${ }^{78}$ Cabe señalar que dichas modificaciones incor-

75 Véase Cerna, Christina, "The Inter-American Commission on Human Rights: its Organization and Examination of Petitions and Communications", en Harris, D. J. y Livingstone, S. (eds.), The Inter-American System of Human Rights, Oxford, Oxford University Press, 1998, pp. 100 y 101.

76 Sepúlveda, César, op. cit., nota 13, p. 243.

77 Ibidem, pp. 246 y 247.

78 Artículo 45. Solución Amistosa. "1. A solicitud de cualquiera de las partes, o por iniciativa propia, la comisión se pondrá a disposición de las mismas, en cualquier etapa del examen de una petición, a fin de llegar a una solución amistosa del asunto, fundada en el respeto de los derechos humanos establecidos en la Convención Americana sobre Derechos Humanos. 2. Para que la comisión ofrezca a las partes actuar como órgano de solución amistosa del asunto será necesario se hayan precisado suficientemente las posiciones y pretensiones de éstas; y que, a juicio de la comisión, el asunto por su naturaleza sea susceptible de solucionarse mediante la utilización del procedimiento de solución amistosa. 3. La comisión podrá aceptar la propuesta de actuar como órgano de solución amistosa formulada por una de las partes si concurren las circunstancias expresadas en el párrafo anterior y si la otra parte expresamente acepta esa vía. 4. La comisión, al aceptar actuar como órgano de solución amistosa podrá designar dentro de sus miembros a una Comisión Especial o a un miembro individual. La Comisión Especial o el miembro así designado informará a la comisión dentro del plazo que ésta señale. 5. La comisión señalará un término para la recepción y obtención de pruebas, fijará fechas para la celebración de audiencias, si proceden, indicará, si es necesario la práctica de una observación in loco que se realizará mediante la anuencia del correspondiente Estado y señalará un término para la conclusión del procedimiento, término que podrá ser prorrogado a juicio de la comisión. 6. Si se llega a una solución amistosa, la comisión redactará un informe que será transmitido a las partes interesadas y comunicado al Secretario General de la Organización de los Estados Americanos para su publicación. Este informe contendrá una breve exposición de los hechos y de la solución lograda. Si cualquiera de las partes en el caso lo 
poraron casi literalmente las propuestas y recomendaciones hechas por César Sepúlveda, a partir del caso ya señalado. ${ }^{79}$

El Reglamento de 1980 fue sustituido por uno nuevo (aprobado en diciembre de 2000), en vigor a partir del 1o. de mayo de 2001, que detalla la tramitación de soluciones amistosas en el artículo $41 .{ }^{80}$

La nueva regulación depuró el procedimiento, haciéndolo más claro y a la vez flexible a la actuación y criterio de la $\mathrm{CIDH}$, con relación a la complejidad de cada caso concreto. Entre las modificaciones más relevantes destaca el hecho de que la solución amistosa debe estar acorde no sólo a lo dispuesto por la $\mathrm{CADH}$, sino también con las disposiciones de la DADDH, y aquéllas de los instrumentos internacionales de derechos humanos aplicables (artículo 41.1), con lo cual se entienden comprendidos inclusive los de carácter universal. Esto permitirá lograr acuerdos más amplios, la implementación de un mayor número de instrumentos internacionales de derechos humanos (incluyendo aquellos que no contienen procedimientos de peticiones), y requerirá análisis más profundo y amplio de cada caso por parte de la CIDH.

solicita, se le suministrará la más amplia información posible. 7. En caso de que la comisión advierta durante la tramitación del asunto que éste por su naturaleza no es susceptible de una solución amistosa; de que algunas de las partes no consienta en la aplicación de este procedimiento; o no muestre una voluntad de querer llegar a una solución amistosa fundada en el respeto a los derechos humanos, la comisión podrá, en cualquier estado del procedimiento, dar por concluida su intervención como órgano de solución amistosa".

79 Sepúlveda, César, op. cit., nota 13, pp. 250 y 251.

80 Artículo 41. Solución amistosa. "1. La comisión se pondrá a disposición de las partes en cualquier etapa del examen de una petición o caso, por iniciativa propia o a solicitud de cualquiera de ellas a fin de llegar a una solución amistosa del asunto fundada en el respeto de los derechos humanos establecidos en la Convención Americana sobre Derechos Humanos, la Declaración Americana y otros instrumentos aplicables. 2. El procedimiento de solución amistosa se iniciará y continuará con base en el consentimiento de las partes. 3. Cuando lo considere necesario, la comisión podrá encomendar a uno o más de sus miembros la tarea de facilitar la negociación entre las partes. 4. La comisión podrá dar por concluida su intervención en el procedimiento de solución amistosa si advierte que el asunto no es susceptible de resolverse por esta vía, o alguna de las partes no consiente en su aplicación, decide no continuar en él, o no muestra la voluntad de llegar a una solución amistosa fundada en el respeto de los derechos humanos. 5. Si se logra una solución amistosa, la comisión aprobará un informe con una breve exposición de los hechos y de la solución lograda, lo transmitirá a las partes y lo publicará. Antes de aprobar dicho informe, la comisión verificará si la víctima de la presunta violación o, en su caso, sus derechohabientes, han dado su consentimiento en el acuerdo de solución amistosa. En todos los casos, la solución amistosa deberá fundarse en el respeto de los derechos humanos reconocidos en la Convención Americana sobre Derechos Humanos, la Declaración Americana y otros instrumentos aplicables. 6. De no llegarse a una solución amistosa, la comisión proseguirá con el trámite de la petición o caso." 
En el Reglamento de 1980, si una solución amistosa era alcanzada, el informe elaborado por la ICHR debía ser transmitido al secretario general de la OEA para su publicación; en el Reglamento de 2001, de conformidad con el artículo 41.5, es la propia comisión quien está facultada para ello.

La víctima y sus familiares tienen un importante papel que desempeñar en el nuevo esquema, en virtud de que la CIDH debe verificar antes de la aprobación del informe sobre la solución amistosa alcanzada, que aquellos han manifestado su consentimiento en el acuerdo. Este es normalmente suscrito por las partes involucradas, y por alguno de los miembros de la comisión, tan pronto como el respectivo intercambio de comunicaciones y las negociaciones respectivas han tenido lugar, con el fin de ser formalizado.

Por último, el nuevo artículo 41.6 señala expresamente que la $\mathrm{CIDH}$ continuará con el examen de la petición si no es alcanzada una solución amistosa del asunto. Como puede observarse, sin haber sido modificada una sola palabra de la CADH, el Reglamento de 2001 ha reorientado el significado y alcance de algunas de sus disposiciones.

Por otra parte, con relación a la incidencia de soluciones amistosas de peticiones individuales en el sistema interamericano, ésta era tan escasa que no eran siquiera contempladas de forma regular en los informes anuales de actividades de la CIDH. Fue precisamente a partir del informe anual de actividades correspondiente a 1997, que la comisión decidió incluir, además de los informes de fondo relativos a peticiones individuales, todo el sistema de peticiones sobre casos individuales ante la comisión y la corte (informes de admisibilidad, inadmisibilidad, medidas cautelares, soluciones amistosas y casos y asuntos presentados ante la Corte Interamericana). ${ }^{81}$

En la siguiente tabla se aprecian los casos que se encontraban siendo tramitados bajo un esquema amistoso por año. ${ }^{82}$

\begin{tabular}{|c|c|c|c|c|c|c|}
\hline 1997 & 1998 & 1999 & 2000 & 2001 & 2002 & 2003 \\
\hline $\begin{array}{l}\text { No se } \\
\text { informa }\end{array}$ & $\begin{array}{l}\text { No se } \\
\text { informa }\end{array}$ & 83 & 91 & 78 & 78 & 84 \\
\hline
\end{tabular}

81 Véase documento OEA/Ser.L/V/II.98; Doc. 6; 17 de febrero de 1998; Original: español.

82 Los datos fueron extraídos de los correspondientes informes anuales de la CIDH, consultables en la página de Internet de la comisión: http://www.cidh.org. 
En la siguiente tabla se muestra el número de informes de solución amistosa publicados.

\begin{tabular}{|c|c|c|c|c|c|c|}
\hline 1997 & 1998 & 1999 & 2000 & 2001 & 2002 & 2003 \\
\hline 1 & 2 & 4 & 13 & 8 & 2 & 11 \\
\hline
\end{tabular}

El número entre casos en trámite amistoso e informes publicados contrasta enormemente y demuestra el largo tiempo que pasa entre la negociación, la formalización del acuerdo y la implementación de los términos del mismo.

Por otra parte, los países con mayor número de informes de solución amistosa publicados son: Ecuador con 22 casos, Argentina con 5, Guatemala con 4, Perú con 3, Chile con 2, Colombia con 2, México con 2, Brasil con 1 y Paraguay con 1 . Tomando en cuenta las cifras de asuntos en trámite, estos números no son un indicador definitivo de cuál de los países es más afecto a la solución amistosa de casos, aunque el caso de Ecuador es incuestionable.

En la siguiente tabla se muestra el número total de casos en trámite por año (cuadro izquierdo), frente al número de casos en trámite de solución amistosa (cuadro derecho).

\begin{tabular}{|c|c|c|c|c|c|c|c|c|c|c|}
\hline 1997 & 1998 & \multicolumn{2}{|c|}{1999} & \multicolumn{2}{|c|}{2000} & \multicolumn{2}{|c|}{2001} & \multicolumn{2}{|c|}{2002} & 2003 \\
\hline $76 \mid \begin{array}{l}\text { No se } \\
\text { informa }\end{array}$ & $945 \begin{array}{l}\text { No se } \\
\text { informa }\end{array}$ & 945 & 83 & 930 & 91 & 936 & 78 & 973 & 78 & \begin{tabular}{l|l|l}
982 & 8
\end{tabular} \\
\hline & \multicolumn{2}{|c|}{8.78} & \multicolumn{2}{|c|}{$9.7\}$} & \multicolumn{2}{|c|}{8.3} & & .01 & \\
\hline
\end{tabular}

En los párrafos siguientes será descrita la fase de solución amistosa de conformidad con la reglamentación vigente, sin dejar de tomar en cuenta que las peticiones interestatales e individuales son reguladas por las mismas disposiciones de la CADH (artículo 46).

\section{Análisis del procedimiento de solución amistosa}

Una vez admitida para trámite una petición, inicia una etapa de fijación de la litis y de las correspondientes posiciones de las partes que culmina con la determinación de la CIDH sobre los méritos para la admisibilidad formal de una petición. Ésta debe ser declarada una vez que han satisfecho diversos requisitos formales y sustantivos, entre los que se en- 
cuentran, hablando en términos generales, que de ser ciertos los hechos constituirían una violación a los derechos objeto del sistema de peticiones, el agotamiento previo de los recursos internos, que la petición sea interpuesta en tiempo, y que no esté siendo examinada a través de otro procedimiento internacional ${ }^{83} \mathrm{o}$, en su caso, que se actualicen algunas de las excepciones a la satisfacción de algunos de éstos. La declaración de admisibilidad de una petición abre la etapa de estudio del fondo del asunto, y también la posibilidad expresa de alcanzar un arreglo amistoso del caso.

Cabe insistir en que si bien está señalada la solución amistosa por la propia CADH (artículo 48.1.f), ésta no ofrece mayores elementos sobre el procedimiento que ha de seguirse en estos casos.

El artículo 45 del Reglamento de la CIDH de 1980 parece que va más allá en virtud de que no sólo autoriza a las partes a solicitar el ofrecimiento de la CIDH sobre la posibilidad de un arreglo amistoso, sino que pueden hacerlo "en cualquier etapa del trámite de una petición". Sin embargo, hasta ahora es usual que el acuerdo amistoso sea alcanzado antes que la comisión publique su informe definitivo sobre el asunto, precisamente luego de emitido el informe de admisibilidad (si es que lo hubo).

En cambio, el reglamento vigente (artículo 41) omite hacer referencia a tal aspecto, de lo cual se infiere que la solución amistosa puede tener lugar en cualquier etapa de la tramitación de un asunto bajo consideración de la comisión e inclusive en etapas posteriores a la decisión de ésta. En este último supuesto se trataría en realidad de un acuerdo amistoso para el cumplimiento cabal de las recomendaciones de la comisión.

En los párrafos siguientes haremos referencia al procedimiento, de conformidad con el Reglamento de la CIDH vigente, y sólo de manera excepcional haremos referencia al Reglamento de 1980.

Llenando algunas de las omisiones de la $\mathrm{CADH}$, el reglamento vigente de la CIDH prevé que el arreglo amistoso puede ser posible únicamente sobre la base del consentimiento de ambas partes. Así, si la oportunidad de un arreglo amistoso proviene de la $\mathrm{CIDH}$, la decisión final acerca de si el asunto es o no resuelto de manera amigable descansa enteramente en la voluntad de las partes. En la actualidad, la voluntad de las partes es exigida durante todo el procedimiento de solución amistosa, toda vez que cualquiera de ellas o ambas pueden en cualquier tiempo so- 
licitar la terminación anticipada de éste o la inaplicación del acuerdo (artículo 41.4 del Reglamento de la CIDH). ${ }^{84}$

En tal sentido, si la propuesta de solución amistosa es aceptada por las partes, la comisión debe actuar como conciliador; con este fin, puede encomendar a uno o más de sus miembros la tarea de facilitar la negociación entre las partes.

En la práctica, el momento en que la comisión se pone expresamente a disposición de las partes con el propósito de poder solucionar el asunto por vía amistosa, si este fuera su deseo, es en el informe en el cual se declara la admisibilidad formal del caso, esto es, una vez que se determina que el mismo posee los méritos para ser decidido en el fondo por la comisión. En casos de violaciones flagrantes y evidentes, incluso se podría ofrecer la solución durante la etapa de tramitación inicial de la queja.

Las audiencias convocadas por la CIDH como parte del trámite de admisibilidad de peticiones o con posterioridad a éste, es un buen escenario para sugerir la posibilidad de un acuerdo amistoso. Es frecuente que ante la presencia del personal o de los miembros de la comisión, las víctimas sientan mayor confianza, y el gobierno se vea "inclinado" a mostrar su voluntad de resolver el asunto de manera amistosa, sobre todo si no existen elementos contundentes para su defensa.

Por lo regular, es el peticionario y no el Estado el primero que acepta la invitación de la CIDH. Con este fin, el primero envía a la comisión los términos bajo los cuales, en su concepto, puede ser alcanzado un acuerdo. Éstos pueden incluir acciones que debe adoptar el gobierno, los plazos, la forma de supervisarlas, y las bases para fijar la compensación que corresponderá a las víctimas, o el monto total de ésta.

Luego de que la CIDH transmite la propuesta señalada al Estado, éste remite sus observaciones y comentarios sobre la oportunidad de la solución amistosa, su voluntad de resolver el asunto por dicha vía y, especialmente, sobre los términos remitidos por el peticionario. Desde luego, no existe siempre un total acuerdo sobre los puntos sugeridos por éste.

Si ambas partes muestran interés en alcanzar un arreglo amistoso, entonces inicia una etapa de comunicaciones y negociaciones informales

84 Cabe señalar que no se exige a las partes que justifiquen o razonen su determinación de dar por terminado el arreglo amistoso, pero por lo regular, se aduce falta de condiciones para esto, o de disposición o buena fe de alguna de las partes. 
entre las partes. Las negociaciones puede llevar a formalizar un acuerdo por escrito o, por el contrario, continuar con el trámite de la queja en la etapa en que se encuentre.

La fase de negociación muestra en ocasiones no sólo la buena voluntad de las partes, sino también los verdaderos fines de sus respectivas posiciones. La habilidad del peticionario para negociar es de la mayor importancia, toda vez que el gobierno por lo regular ofrece aquello a lo que ya se encuentra jurídicamente obligado en los términos de la CADH. El asesoramiento de especialistas es importante con relación al alcance de los términos del acuerdo propuesto.

Posteriormente, si ambas partes acceden, el acuerdo es formulado por escrito y suscrito por sus respectivos representantes, y por los miembros de la CIDH a cargo de monitorear el cumplimiento de los compromisos adquiridos. Sobre este punto, José Miguel Vivanco señala que "los términos de un acuerdo amistoso deben ser aprobados por la comisión, para garantizar que están de acuerdo con el objeto y fin de la convención", ${ }^{85}$ y en la práctica, de hecho lo es.

No obsta poner de manifiesto que todo acuerdo de posible solución amistosa debe fundarse en el respeto a los derechos humanos, no sólo de aquellos en juego en el caso concreto, sino en el marco general provisto por la CADH, y también por la Declaración Americana y otros instrumentos aplicables (artículo 41.5 del Reglamento de la CIDH).

La CIDH debe dedicar sus mejores esfuerzos para mantener el asunto en el esquema amistoso, a menos que encuentre aplicables algunas de las causas de terminación anticipada de dicho procedimiento, como puede ser: que, de conformidad con la naturaleza del asunto, éste no sea susceptible de arreglo amistoso, tal podría ser el caso de violaciones a los derechos humanos considerados como de lesa humanidad o especialmente graves; que la CIDH encuentre que alguna de las partes no consienta en la aplicación del procedimiento amistoso; que alguna de éstas no muestre disposición para alcanzar o cumplir con un acuerdo amigable compatible con el respeto por los derechos humanos; o que el Estado busque con el acuerdo sólo dilatar temporalmente el asunto y con esto la solución definitiva del asunto.

85 Vivanco, J. y Bhansali, L., "Procedural Shortcomings in the Defense of Human Rights: An Inequality of Arms", en Harris, D. J. y Livingstone, S. (eds.), The Inter-American System of Human Rights, Oxford, Oxford University Press, 1998, p. 432. 
Llegada una situación de este tipo, la comisión está facultada para dar por concluida su intervención y con ésta la posibilidad de solución amistosa, pues una decisión de esta naturaleza lleva a continuar con el trámite del asunto en la etapa en que se encuentre (Reglamento de la CIDH en vigor, artículo 41.4 y 41.6).

Subsecuentemente, si el arreglo amistoso se logra, la CIDH debe aprobar un informe en el que se expongan de manera breve los hechos y la solución lograda. Dicho informe, antes de ser publicado, debe ser transmitido a las partes y verificarse el pleno consentimiento de la víctima o de sus derechohabientes con respecto al acuerdo amistoso (Reglamento de la CIDH en vigor, artículo 41.5).

Por el contrario, si el acuerdo amistoso no es alcanzado, la comisión debe, dentro del tiempo límite de 180 días establecido por su propio estatuto, elaborar el informe que contenga los hechos, sus conclusiones y recomendaciones. ${ }^{86} \mathrm{El}$ informe debe ser transmitido sólo al Estado al que se imputa la violación de conformidad con el artículo 50 de la $\mathrm{CADH}$, el cual no está autorizado para hacerlo público. ${ }^{87}$

Si el Estado decide no aceptar las recomendaciones de la CIDH o si, habiéndolas aceptado, no cumple con aquéllas en los términos señalados por ésta, se puede producir algunas de las siguientes consecuencias: 1) Que la comisión decida emitir y publicar un segundo informe que es definitivo, denominado Informe del Artículo 51 por estar previsto en el dicho precepto de la $\mathrm{CADH}$; 2) Que la comisión o algún Estado (tratándose de una petición interestatal), presenten el caso ante la Corte Interamericana de Derechos Humanos, ${ }^{88}$ siempre y cuando el Estado señalado como responsable haya aceptado la competencia contenciosa de esta última.

Debe enfatizarse que si bien la decisión sobre admisibilidad puede ser publicada a través de un informe, ${ }^{89}$ el resto del procedimiento transcurre de forma confidencial hasta que se cumplan los términos de lo pactado y se publique un informe sobre el particular, o si el informe de fondo definitivo es publicado, o el caso es presentado en forma de demanda a la Corte Interamericana.

Con relación a la ejecución del acuerdo de solución amistosa, descansa únicamente en el ámbito de la $\mathrm{CIDH}$; ésta ha sido sumamente cui-

86 Estatuto de la CIDH, artículo 23.2.

87 CADH, artículo 50.

88 CADH, artículos 50, 51 y 61.2 .

89 Artículo 37 del Reglamento de la CIDH vigente. 
dadosa en no hacer público ningún arreglo amistoso alcanzado antes de que los Estados hayan proporcionado evidencia de las acciones sustantivas que han efectuado, y una vez que el peticionario ha manifestado su conformidad con éstas.

Si el Estado no cumple sus compromisos, la comisión puede decidir continuar con el trámite de la petición. El informe de la CIDH sobre el fondo del asunto puede contener una descripción de cómo transcurrió el procedimiento de solución amistosa, las razones para interrumpir el mismo y la decisión de continuar el procedimiento normal, lo cual expone al Estado a una condena aún mayor, ya que la opción infructuosa de arreglo amistoso puede ser indicio de una criticable táctica dilatoria de su parte.

Las disposiciones de la $\mathrm{CADH}$ son aplicables únicamente respecto de soluciones amistosas logradas ante la CIDH. No obstante esto, tal como sucede en el marco del sistema europeo, las partes puede llegar a un acuerdo una vez que el asunto ha sido del conocimiento de la Corte Interamericana. No hay indicios a la fecha de que esto haya ocurrido, pero el Reglamento de la Corte Interamericana de 1997 — anterior al vigente aprobado en noviembre de 2000 y en vigor a partir de junio de 2001 - ya poseía algunas disposiciones sobre dicha posibilidad. ${ }^{90}$

El Reglamento vigente de la Corte Interamericana hace referencia a la solución amistosa dentro del capítulo $\mathrm{V}$ intitulado "terminación anticipada del proceso", específicamente en el artículo 53 en que se señala textualmente: "Cuando las partes en un caso ante la corte comunicaren a ésta la existencia de una solución amistosa, de un avenimiento o de otro hecho idóneo para la solución del litigio, la corte podrá declarar terminado el asunto".

Entre este tipo de casos estarían aquellos en los cuales el acuerdo alcanzado no es compatible o no satisface los derechos establecidos protegidos por el sistema interamericano, o cuando existe evidencia de que la víctima fue de alguna manera presionada o coaccionada a aceptar los términos del acuerdo.

La actualización de alguna de las hipótesis señaladas no obsta para que la corte simplemente proceda a dar por terminado el asunto, puesto que el artículo 54 establece que dicho tribunal tiene la potestad de pro-

90 Véase Reglamento de la Corte Interamericana de Derechos Humanos en vigor a partir del 1 de enero de 1997, artículo 53. El Reglamento de 1992 contenía una disposición similar en el artículo 43. 
seguir el examen del caso a la luz de las responsabilidades que le incumben de proteger los derechos humanos.

Como puede observarse, el procedimiento descrito mantiene en esencia las mismas características de la solución amistosa en el marco de la $\mathrm{CEDH}$. No obstante, dentro del sistema interamericano han surgido todavía cuestiones relevantes sobre el significado y alcance de las disposiciones que regulan el procedimiento, lo cual será abordado en los párrafos siguientes.

\section{La fase de solución amistosa ¿un deber o sólo una facultad de la CIDH?}

La solución amistosa en el sistema europeo es una fase fija que debe ser agotada con el fin de continuar con el examen de la petición, de esta manera, ofrecer la posibilidad de lograr un acuerdo de este tipo no es algo meramente discrecional sino un deber.

Si bien el sistema interamericano posee casi idénticas reglas a las del sistema europeo, el deber de la comisión de invitar a las partes a explorar la posibilidad de un arreglo amistoso ha sido cuestionado ¿Puede la CIDH omitir la fase de solución amistosa discrecionalmente?

Esto da lugar a dos interpretaciones diversas. Andrés Aguilar señala con respecto al artículo 48.1.f de la $\mathrm{CADH}$ : "de la redacción de esta disposición se sigue claramente que se trata de una obligación, y no sólo una facultad más de la comisión";91 José Miguel Vivanco afirma que "sólo recientemente la comisión entendió que se trata de algo obligatorio"; 92 por último, Christina Cerna opina que "toda vez que la noción central de la convención es la convicción de que disputas sobre derechos humanos pueden ser resueltas, la comisión no debe situarse a sí misma en una posición tal, a priori, que excluya cierto tipo de casos en virtud de la naturaleza de las violaciones involucradas, ya que la propia convención no establece una jerarquía de ese tipo". ${ }^{93}$

Una interpretación diferente puede ser que no todos los casos y no todo tipo de violaciones a los derechos humanos son susceptibles de ser resueltas amistosamente. De acuerdo con esta interpretación, depende de la CIDH determinar cuáles casos dan oportunidad para proponer un arre-

91 Aguilar, Andrés, op. cit., nota 69, p. 212.

92 Vivanco, J. y Bhansali, L., op. cit., nota 85, p. 433.

93 Cerna, Christina, op. cit., nota 75, p. 102. 
glo amistoso y cuáles no; en esta última situación la CIDH no debe siquiera consultar a las partes a este respecto, lo cual se considera comprendido en el significado de la frase: "en todos los casos, la solución amistosa deberá fundarse en el respeto de los derechos humanos reconocidos en la Convención Americana sobre Derechos Humanos, la Declaración Americana y otros instrumentos aplicables" (artículo 41.5 del Reglamento de la CIDH vigente).

La CIDH, cuando reformó en 1985 su Reglamento de 1980, siguió la segunda de las posturas indicadas. Por esto, en el artículo 45.7 se establecío: "en el caso de que la comisión encuentre, durante la tramitación del asunto, que el caso, por su propia naturaleza, no es susceptible de arreglo amistoso... en cualquier etapa del procedimiento debe declarar su papel como órgano de conciliación para una solución amistosa como terminado".

El reglamento en vigor cambió el "deber" señalado por una "potestad" (artículo 41.4), enfatizando con esto la discreción de la comisión para determinar el camino a seguir atendiendo a los diversos factores que pueden influir en un caso concreto.

La Corte Interamericana ha tenido la oportunidad de referirse al tema en algunos de sus primeros casos contra Honduras, nos referimos al caso Velásquez Rodríguez, Fairén Garbi y Solís Corrales, y Godínez Cruz. ${ }^{94}$ En todos estos, la corte señaló:

Desde un punto de vista literal, la frase utilizada por el artículo 48.1.f) de la convención, la comisión "se pondrá a disposición de las partes interesadas, a fin de llegar a una solución amistosa", parece establecer un trámite obligatorio. Sin embargo, la corte considera que una interpretación, de acuerdo con el contexto de la convención, lleva al convencimiento de que esa actuación de la comisión debe intentarse sólo cuando las circunstancias de una controversia determinen la necesidad o la conveniencia de utilizar este instrumento, supuestos sujetos a la apreciación de la comisión.

En el caso Caballero Delgado y Santana la corte confirmó sus criterios y resaltó que:

94 Ibidem, pp. 102 y 103. Véase Caso Velásquez Rodríguez. Excepciones Preliminares. Sentencia de 26 de junio de 1987, párr. 44; Caso Fairén Garbi y Solís Corrales. Excepciones Preliminares. Sentencia de 26 de junio de 1987, párr. 49. Caso Godínez Cruz. Excepciones Preliminares. Sentencia de 26 de junio de 1987, párr. 47. También, Caso Caballero Delgado y Santana. Excepciones Preliminares. Sentencia de 21 de enero de 1994, párrs. 26 y 27. 
Lo anterior significa que la comisión posee facultades discrecionales, pero de ninguna manera arbitrarias, para decidir, en cada caso, si resulta conveniente o adecuado el procedimiento de solución amistosa para resolver el asunto en beneficio del respeto a los derechos humanos (Caso Velásquez Rodríguez, Excepciones Preliminares, párr. 45; Caso Fairén Garbi y Solís Corrales, Excepciones Preliminares, párr. 50; Caso Godínez Cruz, Excepciones Preliminares, párr. 48). ${ }^{95}$

La decisión de la corte apoyó la interpretación que la CIDH había dado al artículo 48.1.f de la convención, que plasmó en la parte respectiva de su reglamento. Sin embargo, la corte claramente señaló que las facultades de la CIDH no eran de modo alguno absolutas.

Posteriormente, la corte tuvo la oportunidad de enriquecer su análisis sobre la solución amistosa, en el mencionado caso Caballero Delgado y Santana, en el que la corte estableció:

La comisión no tiene facultades arbitrarias en esta materia. Es muy clara la intención de la convención respecto del papel conciliador que debe cumplir la comisión antes de que un caso sea enviado a la corte o publicado.

Sólo en casos excepcionales y, naturalmente, con razones de fondo, puede la comisión omitir el procedimiento de la conciliación porque está de por medio la protección de los derechos de las víctimas o de sus familiares. No parece ser suficiente decir, como lo hace la comisión, que no se acudió a este procedimiento simplemente por razón de la "naturaleza" del asunto. ${ }^{96}$

Adicionalmente, la corte se refirió al rol de la CIDH respecto de la solución amistosa, en los siguientes términos:

En un procedimiento de solución amistosa es indispensable la intervención y decisión de las partes involucradas. Aún interpretando literalmente las disposiciones de la convención y haciendo caso omiso del reglamento de la comisión, ésta solamente podría sugerir a las partes entablar las conversaciones enderezadas a la solución amistosa pero no podría, por carecer de poder para ello, decidirla. La comisión debe propiciar el acercamiento pero sus resultados no dependen de ella. De alcanzarse el acuerdo 
debe ella cerciorarse de que los derechos humanos hayan sido adecuadamente defendidos [cursivas agregadas]. ${ }^{97}$

De acuerdo con la opinión de Christina Cerna, esta decisión modificó la práctica seguida hasta entonces por la comisión en virtud de que a partir de este momento ésta se dirigiría a las partes con el fin de conocer la voluntad de éstas para alcanzar un arreglo amistoso. Si una o ambas partes rechazaban la invitación de la comisión, ésta raramente realizaba esfuerzos adicionales para sugerir el arreglo o para alcanzarlo; así, parece que la voluntad de las partes y no la determinación exclusiva de la comisión es la que determinaba la posibilidad de una solución amistosa. ${ }^{98}$

En realidad, los esfuerzos de la CIDH respecto del procedimiento de solución amistosa han obedecido a la naturaleza de los casos que ha tenido que enfrentar, y a la actitud de los Estados mostrada cuando son señalados como transgresores de derechos humanos. Aún más, parece que la intención de los Estados al impugnar la posición de la comisión en los casos ante la corte, han sido dirigidas a lograr la inadmisibilidad de éstos, por lo que sus argumentos están inclinados sobre todo a este propósito y no al mejoramiento del sistema a favor de las víctimas.

\section{Algunas ventajas y desventajas de la solución amistosa de peticiones sobre derechos humanos}

La solución amistosa como una forma alternativa de resolver una petición de derechos humanos posee algunas ventajas y desventajas para cada una de las partes involucradas, principalmente en comparación con las opciones de terminación última del procedimiento de peticiones, ya sea la emisión, publicación y seguimiento de un informe definitivo o la presentación del caso ante la Corte Interamericana y la emisión de una sentencia condenatoria para el Estado. ${ }^{99}$

Las ventajas de la solución amistosa son más claras cuando la naturaleza del caso lo permite, y la voluntad, posiciones y fines de las partes

97 Ibidem, párr. 30.

98 Cerna, Christina, op. cit., nota 75, pp. 102 y 103.

99 No obstante esto, para algunos autores la solución amistosa es un proceso que brinda razones para la satisfacción y complacencia de todas las partes, pero que formalmente da por terminado el procedimiento, sin que haya ganadores ni perdedores. Harris, D. J. et al., op. cit., nota 25 , p. 600 . 
están a favor de resolver el asunto de esta manera. Algunos aspectos positivos y negativos son los siguientes.

Para el Estado involucrado, el arreglo amistoso significa limitar el daño político que un fallo desfavorable y ampliamente publicado de parte de la corte podría dar lugar, y posiblemente limitar el costo involucrado en continuar la defensa de una causa perdida. ${ }^{100}$ Lo que es más, un acuerdo generoso a favor de la víctima podría hacer al Estado objeto de opiniones positivas respecto a su compromiso hacia los derechos humanos, no obstante la violación cometida. Tal como lo ha afirmado la Corte Interamericana de Derechos Humanos:

Si una parte tiene interés en la solución amistosa puede proponerla. En el caso del Estado y frente al objeto y fin del tratado, que es la defensa de los derechos humanos en él protegidos, no podría entenderse esa propuesta como un reconocimiento de responsabilidad sino, al contrario, como un cumplimiento de buena fe de los propósitos de la convención. ${ }^{101}$

Los Estados por lo regular analizan cuidadosamente las consecuencias de un arreglo amistoso, teniendo en mente el impacto internacional e interno del caso. Desafortunadamente, no en todas las ocasiones la posibilidad de remediar un daño ocasionado es el único factor sujeto a consideración.

Por lo que se refiere al peticionario, el beneficio podría consistir en tener certeza acerca de la materia de la disputa y, en el momento más anticipado posible, de la reparación, si resulta procedente, por los daños ocasionados. ${ }^{102}$ Además, el arreglo amistoso asegura una terminación positiva que de otra manera dependería de procedimientos lentos, que no garantizarían un fallo favorable; ${ }^{103}$ aún más, el carácter flexible del procedimiento de solución amistosa permite la negociación de términos variados, por esto, puede o no incluir una reparación en dinero y/o acciones legislativas o administrativas; el arreglo puede comprender más que lo que una decisión judicial condenatoria podría ofrecer.

100 Idem; véase también Dijk, P. van y Hoof, G. J. H. van, op. cit., nota 15, p. 119; Clements, L., op. cit., nota 27, p. 56.

101 Caso Caballero Delgado y Santana..., cit., nota 94, párr. 30.

102 Dijk, P. van y Hoof, G. J. H. van, op. cit., nota 15, p. 119; véase también Harris, D. J. et al., op. cit., nota 25 , p. 600.

103 Dijk, P. van y Hoof, G. J. H. van, op. cit., nota 15, p. 119. 
No obstante esto, los beneficios mencionados a favor de las víctimas parecen siempre relativos. Algunos factores deben ser tomados en consideración: el largo camino que éstas deben seguir hasta obtener aquello a lo que tenían derecho desde el inicio del asunto; los amplios recursos jurídicos y procedimientos que deben ser agotados; y el costo y tiempo que debe dedicarse para poder acudir a instancias internacionales.

Teniendo en mente estos factores, cuya incidencia es frecuente, ninguna reparación o compromisos serían suficientes para compensar completamente las consecuencias directas e indirectas de una violación a derechos humanos. Cuando sucede que el Estado manifiesta su voluntad para hacer lo que en realidad está obligado a realizar, por virtud del derecho internacional de los derechos humanos, cualquier arreglo amistoso de esta naturaleza parece una broma del peor gusto tanto para la víctima o el peticionario y para los órganos internacionales de supervisión.

Podría argumentarse que la situación podría ser peor si los Estados no hubieran tenido la voluntad para obligarse por un tratado internacional, o que los mecanismos internacionales fueron creados para atender sólo y únicamente los casos de la peor y excepcional naturaleza. Sin embargo, estos mismos argumentos están a favor de soluciones amistosas ejemplares y de las consecuentes medidas preventivas al interior del Estado correspondiente, con el fin de que la violación cometida no se vuelva a repetir.

Para los órganos de supervisión, la solución amistosa ayuda a reducir el número de casos a decidir, y para el sistema completo, dicho tipo de arreglos podría motivar al resto de los Estados partes a seguir un ruta similar. ${ }^{104}$

Si se tiene en cuenta la pobre situación del cumplimiento de los Estados a los compromisos asumidos en virtud de los tratados de derechos humanos, no hay duda de que la solución amistosa de peticiones parece una opción valiosa, sino es que la única que en ocasiones tienen las víctimas para obtener alguna reparación oportuna. 


\section{Algunas violaciones a los derechos humanos que podrían ser inadecuadas para un arreglo amistoso}

La cuestión acerca de hasta qué punto la CIDH tiene el deber de ofrecer y buscar un arreglo amistoso entre las partes está estrechamente ligada con otro tema no menos importante acerca del tipo de violaciones a los derechos humanos que no son susceptibles de solucionarse mediante una solución amistosa.

Recordando la opinión de sir Humphrey Waldock, quien fue presidente de la ahora inexistente Comisión Europea de Derechos Humanos, las instituciones previstas en la $\mathrm{CEDH}$ fueron establecidas originalmente con el principal propósito de resolver amistosamente las posibles transgresiones a dicho tratado. Esto es de utilidad para explicar claramente porque en el sistema europeo todo tipo de casos y por consiguiente de violaciones a los derechos establecidos en la $\mathrm{CEDH}$, merecen al menos la oportunidad de explorar un posible arreglo amistoso.

El éxito de una solución amistosa depende de la voluntad de ambas partes, de los esfuerzos de los órganos de supervisión para garantizarla y, principalmente, de las acciones del Estado y los recursos que destine éste para cumplir con sus compromisos.

En el sistema interamericano, la cuestión acerca de qué tipo de violaciones a los derechos humanos, o sobre qué circunstancias puede hacer a un caso inapropiado para un arreglo amistoso, permanece sin ser resuelta en definitiva. Sin embargo, la CIDH ha señalado el tema en algunos casos remitidos a la corte, y algunos autores han manifestado sus opiniones al respecto.

En opinión de Andrés Aguilar, un caso no sería susceptible de solución amistosa por "la actitud de las partes involucradas, o por la propia naturaleza o porque la gravedad de la violación no da oportunidad de una reparación adecuada. Este sería el caso de, por ejemplo, la privación ilegal de la vida, o los tratos crueles, inhumanos y degradantes". 105

El mismo autor va más allá al afirmar que la solución amistosa puede funcionar unicamente en los casos de peticiones interestatales, en las cuales está completamente justificada. ${ }^{106}$ 
Christina Cerna difiere de las anteriores ideas en cuanto expresa, al tomar como referencia las decisiones de la Corte Interamericana en los casos contra Honduras, que en los casos que involucran desapariciones forzadas es sumamente difícil alcanzar un arreglo amistoso que pudiera reflejar el respeto al derecho a la vida, a los tratos humanos y a la libertad personal. La imposibilidad de resolver de manera amistosa este tipo de casos es incluso más fuerte cuando el Estado se muestra cooperativo con la comisión, pero niega que los hechos ocurrieron. ${ }^{107}$

César Sepúlveda enfatiza que ninguna solución amistosa debería ser ofrecida en los casos de detención ilegal o prolongada sin ser presentado ante un juez, tortura, ejecuciones sumarias y desapariciones forzadas. ${ }^{108}$ Para este autor, la comisión podría rechazar cualquier propuesta de solución amistosa hecha con la intención evidente de servir como un medio de retrasar la adopción de una decisión sobre el fondo del asunto. ${ }^{109}$

Los órganos de supervisión de aquellos tratados que admiten la solución amistosa de peticiones deben tomar ventaja de sus atribuciones y experiencia para detectar aquellos casos que podrían no ser susceptibles de ser resueltas a través del procedimiento mencionado. Además, todos los tratados a los que se ha hecho alusión estipulan que cualquier arreglo debe ser alcanzado sobre la base del respeto a los derechos humanos. Los órganos de supervisión deben dar a esta disposición el alcance y sentido más amplios posibles y utilizarla para apoyar cualquier decisión que adopten al respecto.

En la mayoría de las ocasiones, la finalidad del Estado es evitar la condena pública internacional de ser señalado como responsable de serias violaciones a los derechos humanos. Por tal motivo, para que una arreglo amistoso sea aceptable sobre estas bases, debe incluir como mínimo para el Estado los mismos compromisos que le corresponderían si el caso fuera decidido en su contra y, por supuesto, aquellas acciones para prevenir la incidencia de situaciones similares; así, la violación es reparada bajo los estándares más altos y el Estado evita la condena internacional e interna adversas de un informe o de un fallo condenatorio. 
A manera de conclusión, es posible afirmar, con una visión optimista del tema, que en un futuro la solución amistosa será el mecanismo normal de tramitación y terminación de peticiones internacionales, y que sólo de manera excepcional se llegará a la emisión de informes o de sentencias; para que esto ocurra, no hace falta otra cosa que un verdadero compromiso y voluntad de los Estados hacia el respeto a los derechos humanos. 